\title{
Characterization and reactivity of silicatic consolidants
}

\author{
Elisabetta Zendri, Guido Biscontin, Ilaria Nardini *, Sara Riato \\ Dipartimento di Scienze Ambientali, Università Ca' Foscari di Venezia, Via Torino, 155/B, 30175 Venice, Italy
}

Received 14 March 2005; received in revised form 1 January 2006; accepted 15 January 2006

Available online 28 August 2006

\begin{abstract}
In this study some results on the reactivity of silicatic consolidants employed for the conservation of valuable artistic and cultural porous materials are discussed. In particular, a colloidal suspension of silica made by particles with an average diameter of 10 $15 \mathrm{~nm}$, a sodium silicate and an ethyl silicate consolidant are studied. The chemical-physical characterization of xerogels achieved from the examined products were carried out determining the superficial area (BET method) and the average dimension of particles (SAXS) while the chemical structure of xerogels were investigated through NMR MAS spectroscopy of the ${ }^{29} \mathrm{Si}$ nucleus. The investigation on reactivity between silica and stone support was executed by mixing consolidants with calcite and quartz powder to simplify as much as possible the system otherwise very complex. On silica produced by the three examined consolidants structural differences are revealed and these diversities can be responsible for the dissimilar reactivity of the silicatic systems towards the stone, in particular with regard to the carbonatic component.
\end{abstract}

(c) 2006 Elsevier Ltd. All rights reserved.

Keywords: Consolidation; Silicates; Reactivity; ${ }^{29} \mathrm{Si}$ NMR MAS spectroscopy

\section{Introduction}

The porous materials, as stones and plasters, exposed to the external environment are subjected to chemical-physical decay processes that produce the loss of the consistence of the material. The phenomenon is of particular importance when it involves valuable architectural and artistic works, like masonry of historical buildings or mural paintings. The conservation project of these materials includes a consolidation intervention for restoring the physicalmechanical characteristics of the support and in particular the cohesion between material particles and their adhesion to the non-deteriorated support. Usually this operation is carried out applying polymeric compounds in organic solvent or in inorganic products [1-3].

In general the polymeric products in organic solvent have demonstrated to own good consolidant properties but also some limits related above all to the different behaviour towards the water of the consolidated material

\footnotetext{
${ }^{*}$ Corresponding author. Tel.: +39 0412346737; fax: +39041 2346729.

E-mail address: nardini@unive.it (I. Nardini).
}

compared to the original one. Besides colour variations of the treated support are often observed and they are not always acceptable in the restoration field.

The inorganic consolidants and most of all the consolidants with a basis of silica react reducing the porosity of the material which becomes more compact and less susceptible to the water action. They have less cohesive property than the organic consolidants but they are most compatible with the support that shows a less heterogeneous behaviour in relation with water both in liquid and in vapour state. In particular sodium silicate, ethyl silicate and a colloidal suspension of silica made of particles with an average diameter of $10-15 \mathrm{~nm}$ [1] are the most preferably used among the inorganic consolidants made by silica. The application of these products causes after many reactions the formation of amorphous silica that acts as a consolidant and it is made by a disorderly and continuous lattice of silica tetra-coordinated tetrahedrons that make rings with 3,4 , $5,6,7$ and 8 atoms of silicium. This structure contains numerous silanolic $\mathrm{Si}-\mathrm{OH}$ groups, which however give hygroscopicity to the system, in particular where an interruption of lattice structure occurs $[4,5]$. 
Initially the sodium silicate, the ethyl silicate and the colloidal silica, that are the objects of this study, form a gel of amorphous silica that afterwards transforms itself in xerogel because of the evaporation of solvent and assumes characteristics strictly correlated with the condition of the solvent evaporation process. It could be put forward the hypothesis that the consolidant action is exercised by the aerogel filling the accessible porous of stone [6] but it is not excluded that it could be influenced by the silicatic structures reactivity with support [7]. There is not much research on the subject but the knowledge of interactions between consolidant and support could be of great applicative interest; in fact it could allow to modify the entity of this interaction in relation to the conservation state of the support and its chemical nature.

In this study, some results on the reactivity of the sodium silicate, ethyl silicate and colloidal silica with calcium carbonate and quartz, that are the principal compounds of the stone used in historical buildings, are reported. In the first part of the research the xerogels obtained from the three silicatic systems are characterized; afterwards the chemical reactivity of xerogels are studied mixing them with calcite and quartz because they are system well-known and recognizable for the employed techniques and facilitate the interpretation of the results.

In this work, the data obtained by ${ }^{29} \mathrm{Si}$ MAS spectroscopy on samples coming from the support-consolidant reactivity are discussed. This technique has already given interesting results in studies on the interaction between binder and aggregate of mortars with fragments of crushed bricks and on the stone decay after consolidant treatment $[8,9]$.

Tests correlated to some properties of the products were carried out in order to evaluate applicative aspect. The capacity of the products to penetrate into real samples and how they distribute on supports were considered determining at different depth the porosity and the porous distribution in function of cumulative volume. The cohesive capacity was measured by a method set up in laboratory and designed in expectation of an employment in building yards.

\section{Experimental method}

\subsection{Samples}

Table 1 reports some physical characteristics of the products employed in this study which are available in commerce at different concentration level.

The products were prepared to obtain the same dry weight/humid weight rate (silica content after solvent evaporation process). The supports employed were quartz and calcium carbonate. In this way many problems due to the presence of impurities and different porosity of the support were overcome. Quartz was ground and it was used the fraction with a grain size smaller than $38 \mu \mathrm{m}$; calcium car-
Table 1

Chemical-physical characteristics of the silicatic consolidants

\begin{tabular}{llllll}
\hline Consolidant & $\begin{array}{l}\text { Silica/ } \\
\text { (solvent }+ \\
\text { silica) } \\
\text { product } \\
\text { weight }(\%)\end{array}$ & $\begin{array}{l}\text { Viscosity } \\
(\mathrm{cp})\end{array}$ & $\mathrm{pH}$ & $\begin{array}{l}\text { Solution } \\
\text { density } \\
\left(\mathrm{g} / \mathrm{cm}^{2}\right)\end{array}$ & $\begin{array}{l}\text { Dry product } \\
\text { density } \\
\left(\mathrm{g} / \mathrm{cm}^{3}\right)\end{array}$ \\
\hline $\begin{array}{l}\text { Colloidal } \\
\text { silica }\end{array}$ & 32 & 3.1 & 9.8 & 1.2 & 2.1 \\
$\begin{array}{c}\text { Sodium } \\
\text { silicate }\end{array}$ & 31 & 3.2 & 11.1 & 1.2 & 2.1 \\
$\begin{array}{c}\text { Ethyl } \\
\text { silicate }\end{array}$ & 31 & 2.5 & 6.1 & 0.9 & 1.8 \\
\hline
\end{tabular}

bonate was a standard product $99 \%$ with a fine grain size (smaller than $38 \mu \mathrm{m}$ ).

\subsection{Xerogel characterization}

After evaporation of the water in air $\left(T=19^{\circ} \mathrm{C}\right.$, $\mathrm{HR}=65 \%$ ) the products were dried in the same ambient temperature and with a relative humidity of about $10 \%$.

The xerogels were characterized using different methodologies:

a. Measures of the specific area by BET method (Sorptomatic 1900 Fison Instruments) and by small angle scattering of X-ray (using a Kratky room with a point to point counter and a $\mathrm{Cu} \mathrm{K} \alpha$ radiation) [10]. This technique was employed to verify the data obtained by the BET method; in fact it can feel the effects of the presence of different adsorbed water quantities in the three xerogels.

b. NMR measures of the 29 silicium nucleus (Varian UNITY 400 with resonance frequency ${ }^{1} \mathrm{H}$ equal to $400 \mathrm{MHz}$ ) were carried out on xerogels. The calibration of the abscissa scale was made comparing with the zeolite $\mathrm{X}$ spectrum used as standard and the spectra were deconvoluted into individual Lorentzian functions [11$13]$.

\subsection{Consolidant-support interaction investigation}

The study was conducted on systems obtained by mixtures of different consolidants both with calcite and quartz in 1:1 molar rate. The mixtures were exposed at the air and at $\mathrm{RH}=65 \%$ for enough time to guarantee the xerogel formation (60 days). The mixtures were kept at a relative humidity of about $10 \%\left(T=19^{\circ} \mathrm{C}\right)$. The interaction between silica, coming from the different consolidants, and calcite or quartz was studied by ${ }^{29} \mathrm{Si} \mathrm{NMR}$ spectroscopy using the same conditions described in the previous paragraph.

\subsection{Determination of products distribution into support}

The analyses were carried out on portion of different mortar samples, considering different depth range of 
$0-0.5 \mathrm{~cm}, 0.5-1.0 \mathrm{~cm}$ and $1.0-1.5 \mathrm{~cm}$. All samples were treated with a same quantity of product equal to $4.5 \%$ in weight.

The porous values and the distribution were compared to the data of the non-treated mortars. The porosity measures were repeated three times for each sample using a CE Instrument Pascal 240 mercury porosimeter and following the cultural heritage regulations [14].

\subsection{Cohesion measure}

The determination of the cohesion grade was set up with an equipment made by a drill fixed on a vertical support and connected with a roll whose rotation is proportional to the covered space by the tip of the milling machine on the sample. Graph paper is fixed on the roll and in regular intermissions the covered space of the mill was plotted.

For every sample a mill with a diameter of $12 \mathrm{~mm}$ was employed, using the minor rotation velocity and greater available torque of the drill motor; the weight exerted on samples was constant and equal to $3.8 \mathrm{~kg}$. The values of penetration speed $(\Delta s / \Delta t)$ were extracted from the data obtained and they are reported in a diagram in space function for each sample. The tests were carried out on proper mortar samples prepared in laboratory characterized by a composition of $20 \%$ calcium carbonate and $80 \%$ silicate with well-known and constant values of porosity. The mortar samples were treated with the same quantity of product and for each consolidant ( $4.5 \%$ in weight) five measures of the cohesion were tested. The analysis was carried out on the samples prepared in the same manner of the samples that were subjected to the porosimetric analysis.

\section{Results and discussion}

\subsection{Xerogel characterization}

\subsubsection{Measure of specific area by BET method and small angle scattering of $X$-rays}

The superficial area measurements of silica by BET method pointed out that from the colloidal suspension it was obtained a product with an area of about $150 \mathrm{~m}^{2} / \mathrm{g}$, while from sodium silicate and ethyl silicate were obtained products with an area included into the $8-10 \mathrm{~m}^{2} / \mathrm{g}$ range. The great superficial area of colloidal silica is due to the small dimensions of the particles and it was evaluated by SAXS diffractometry by which it was obtained an average diameter value of $13 \mathrm{~nm}$ to which a superficial area of $220 \mathrm{~m}^{2} / \mathrm{g}$, near to the value given by BET method corresponds. It is important to consider that this technique can evaluate a superficial area so restricted to the only open porous while the low angle diffractometry permits to determine the entire area of the examined sample.

\subsubsection{Measure of ${ }^{29}$ Si by NMR MAS spectroscopy}

The ${ }^{29} \mathrm{Si}$ NMR spectroscopy carried out on xerogel coming from the colloidal suspension evidenced the presence of two signals, one, predominant, at $-114 \mathrm{ppm}$, the second one at $-103 \mathrm{ppm}$ which correspond to $\mathrm{Q}^{4}$ and $\mathrm{Q}^{3}$ type structures relative to tri-dimensional and planar systems (Fig. 1). The analysis on xerogel coming from sodium silicate indicates the presence of three signals at $-110,-99$ and $-90 \mathrm{ppm}$, in which the $\mathrm{Q}^{3}$ (planar) type structure predominates and $\mathrm{Q}^{2}$ (mono-dimensional chains) linear type structures appear (Fig. 2). A similar spectrum was obtained from the ethyl silicate in which $\mathrm{Q}^{3}$ tri-dimensional type structures seem to be predominant (Fig. 3).

Table 2 shows the percentage ratio of the areas corresponding to the peaks of the different structures $\mathrm{Q}^{4}, \mathrm{Q}^{3}$, $\mathrm{Q}^{2}$ and $\mathrm{Q}^{1}$ on the xerogels and on the mixtures with calcium carbonate and quartz.

The values of the relative ratios indicate, as just observed in NMR spectra, the prevalence of the $\mathrm{Q}^{4}$ structure on the xerogel coming from colloidal silica and the $\mathrm{Q}^{3}$ structure on the xerogel coming from ethyl silicate and sodium silicate. In these last two xerogels the contribution of planar structures on the entire complex structure is very similar (78 and 72 ), while the $\mathrm{Q}^{4}$ type structures give nearly a double contribution on the xerogel coming from ethyl silicate compared with the sodium silicate's one in

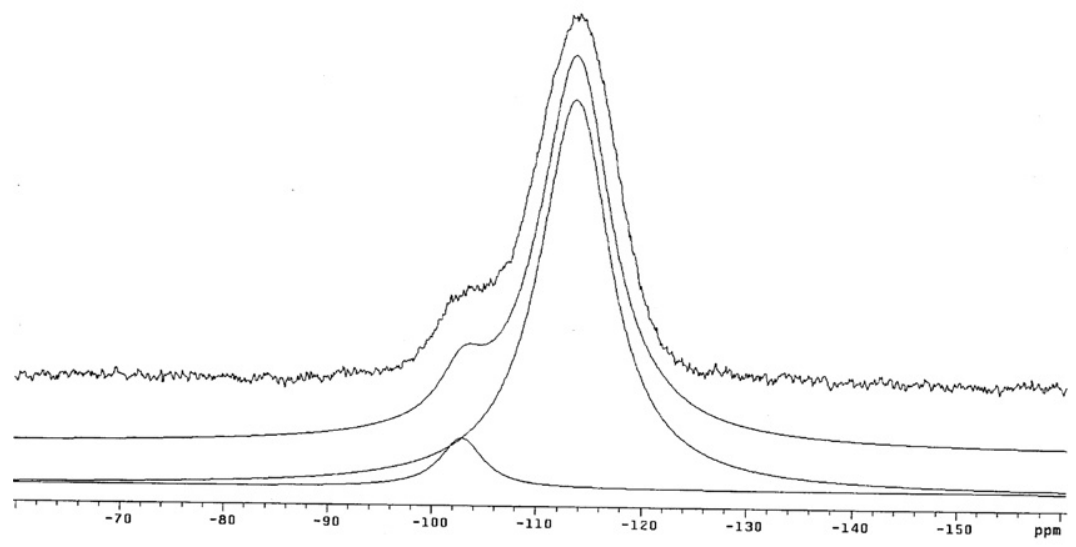

Fig. 1. ${ }^{29} \mathrm{Si}$ NMR spectrum of colloidal silica gel. 


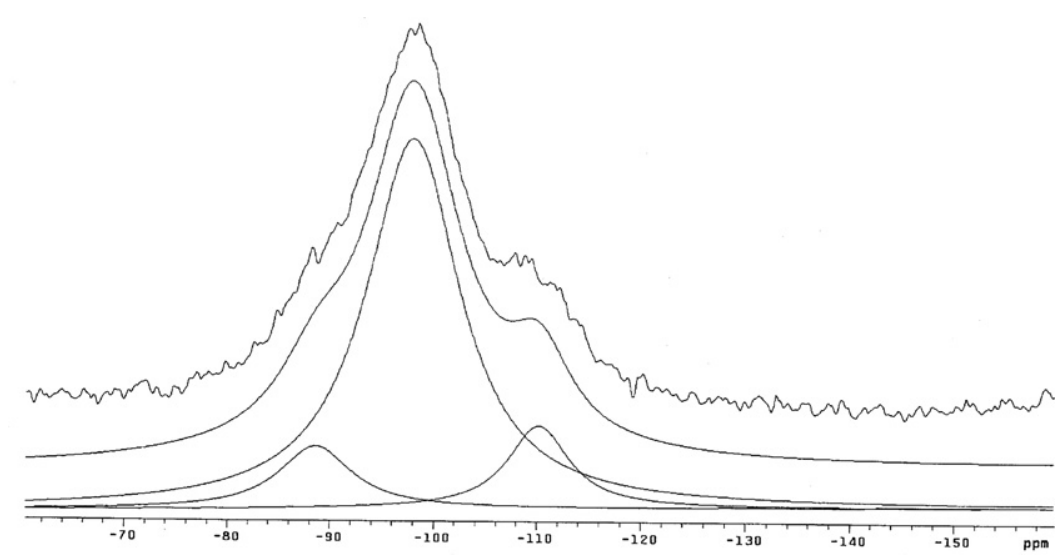

Fig. $2 .{ }^{29} \mathrm{Si}$ NMR spectrum of xerogel coming from sodium silicate.

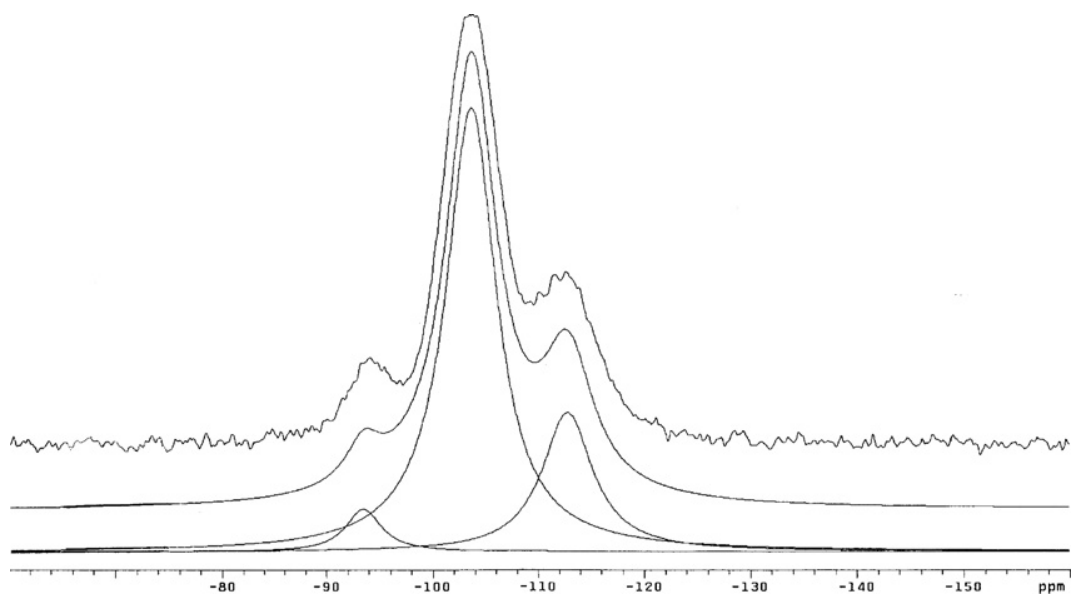

Fig. 3. ${ }^{29} \mathrm{Si}$ NMR spectrum of xerogel coming from ethyl silicate.

which the $\mathrm{Q}^{3} / \mathrm{Q}^{4}$ and $\mathrm{Q}^{3} / \mathrm{Q}^{2}$ ratios substantially are the same.

\subsection{Consolidant-support interaction}

\subsubsection{Silica-calcium carbonate system}

Figs. 4-6 show the ${ }^{29} \mathrm{Si}$ NMR spectra of the three xerogels with calcium carbonate. Table 2 points out the per-

Table 2

Percentage ratio of the areas of each $\mathrm{Q}^{i}$ peak on xerogels and on mixtures in connection with the sum of the total area of peaks

\begin{tabular}{llccl}
\hline System & $\mathrm{Q}^{4} / \sum \mathrm{Q}^{i}$ & $\mathrm{Q}^{3} / \sum \mathrm{Q}^{i}$ & $\mathrm{Q}^{2} / \sum \mathrm{Q}^{i}$ & $\mathrm{Q}^{1} / \sum \mathrm{Q}^{i}$ \\
\hline Colloidal silica & 93 & 7 & 0 & 0 \\
$\quad \begin{array}{l}\text { Colloidal silica }+ \\
\quad \text { calcium carbonate }\end{array}$ & 85 & 15 & 0 & 0 \\
$\quad$ Colloidal silica + quartz & 92 & 8 & 0 & 0 \\
$\quad$ Sodium silicate & 12 & 78 & 11 & 0 \\
$\quad$ Sodium silicate + & 31 & 57 & 12 & 0 \\
$\quad$ calcium carbonate & & & & \\
Sodium silicate + quartz & 21 & 61 & 18 & 0 \\
$\quad$ Ethyl silicate & 23 & 72 & 5 & 0 \\
$\quad \begin{array}{l}\text { Ethyl silicate + } \\
\quad \text { calcium carbonate }\end{array}$ & 43 & 34 & 19 & 4 \\
Ethyl silicate + quartz & 46 & 49 & 5 & 0 \\
\hline
\end{tabular}

centage ratios of the areas corresponding to the peaks of the different structures $Q^{4}, Q^{3}, Q^{2}$ and $Q^{1}$.

3.2.1.1. Colloidal silica and calcium carbonate mixture. Substantial differences with the structure of xerogel coming from the consolidant are not evident (Fig. 4), but the values showed in Table 2 indicate a double contribution of $\mathrm{Q}^{3}$ structure in comparison with the xerogel.

3.2.1.2. Sodium silicate and calcium carbonate mixture. Fig. 5 shows the ${ }^{29} \mathrm{Si}$ NMR spectrum of the mixture from which there are no clear and substantial differences with the xerogel. Also in this case more information are given from the lecture of the Table 2 data from which a substantial decrease of $\mathrm{Q}^{3}$ structure comes out while there is a triple contribution of the $\mathrm{Q}^{4}$ structures. In this case, the calcium carbonate acts in the opposite direction in comparison with colloidal silica and calcium carbonate mixture and it increases the part of the tri-dimensional structures to the detriment of the planar structures.

Important differences appear instead in the mixture with sodium silicate and calcium carbonate: the signals corresponding to $\mathrm{Q}^{4}, \mathrm{Q}^{3}$ and $\mathrm{Q}^{2}$ assume a more tight and lengthened shape and a new signal at $-89 \mathrm{ppm}$ 


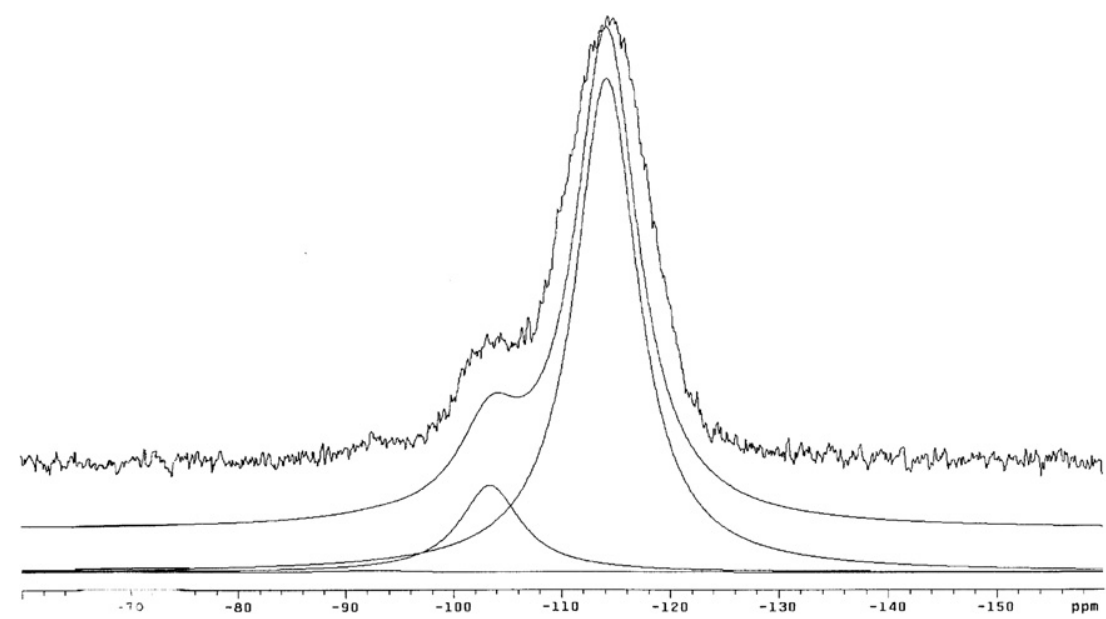

Fig. 4. ${ }^{29} \mathrm{Si}$ NMR spectrum of gel coming from colloidal silica and calcium carbonate mixture.

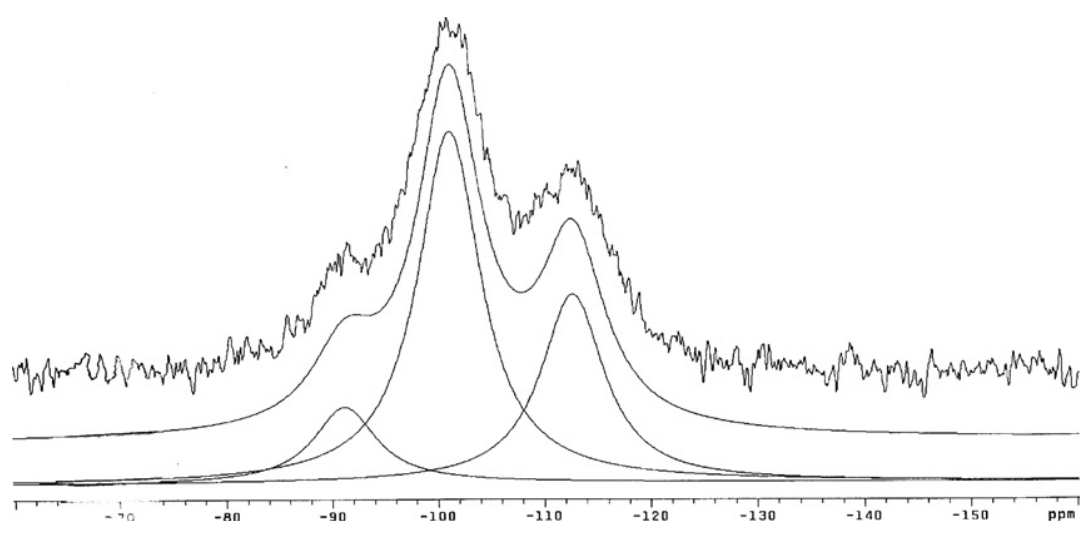

Fig. $5 .{ }^{29} \mathrm{Si} \mathrm{NMR}$ spectrum of gel coming from sodium silicate and calcium carbonate mixture.



Fig. $6 .{ }^{29} \mathrm{Si} \mathrm{NMR}$ spectrum of xerogel coming from ethyl silicate and calcium carbonate mixture.

corresponding to $\mathrm{Q}^{1}$ structure relative to dimers or to terminal group in chains appear (Fig. 6). The different shape of the signals could be index also of a system tendency to a greatest structural order.
3.2.1.3. Ethyl silicate and calcium carbonate mixture. The considerable structural differences induced by calcium carbonate presence are shown in Table 2 . The contribution of the $\mathrm{Q}^{3}$ structures is halved, the $\mathrm{Q}^{4}$ structures's one dupli- 
cates and the contribution of the $\mathrm{Q}^{2}$ structures quadruplicates, besides it appears an important contribution of $\mathrm{Q}^{1}$ structures. The calcium carbonate seems to aid to the development of space and planar structures to the prejudice of planar's ones. The shape of peaks can indicate the presence of crystalline systems, in particular in $\mathrm{Q}^{1}$ and $\mathrm{Q}^{2}$ structures are related to linear and monomeric structures. The calcium carbonate modifies in a significant way the xerogel structure obtained from the three consolidant products. The predominant presence of tri-dimensional $\mathrm{Q}^{4}$ systems seems to reduce the reactivity of xerogel with calcium carbonate. The $\mathrm{Q}^{3}$ systems appear to promote the reactivity with calcium carbonate and to form tridimensional and linear structures. In applicative terms this fact could indicate that the xerogels with a development of silica in "open" systems, like the planar ones, are generally more reactive towards the carbonatic supports.

The ethyl silicate mixing with calcium carbonate seems to modify in considerable manner the original structure and that is underlined by the presence of shorter linear chains of tetrahedral silica or dimeric forms. It could correspond to an effective chemical interaction between the consolidant product and calcium carbonate that involves the formation of linear silicatic structures, while the different shape of signals could indicate the general tendency to a greater order of the already presented silicatic structures maybe induced by calcium carbonate presence.

An analogous behaviour was revealed also in the case of mixture made from kaolin with lime studied to evaluate the crushed brick mortar system reactivity [8].

\subsubsection{Silica-quartz system}

The three products mixed with quartz produce small structural modifications corresponding to a low increase of the more complex $\mathrm{Q}^{3}$ and $\mathrm{Q}^{4}$ type structures (Figs. 7-9).

3.2.2.1. Colloidal silica and quartz mixture. Variations in the xerogel structure are not observed and the contribution of every structures remains nearly unchanged (Table 2).

\subsubsection{Sodium silicate and quartz mixture. Also in this case} there is not observed structural changes in comparison with the xerogel coming directly from the consolidant (Fig. 8).

Nevertheless the contribution correlated to the different structures suffers some modifications: the percentage of $\mathrm{Q}^{3}$ systems decrease and the $\mathrm{Q}^{2}$ and $\mathrm{Q}^{4}$ systems are favoured in the same measure (Table 2).



Fig. $7 .{ }^{29} \mathrm{Si} \mathrm{NMR}$ spectrum of xerogel coming from colloidal silica and quartz mixture.

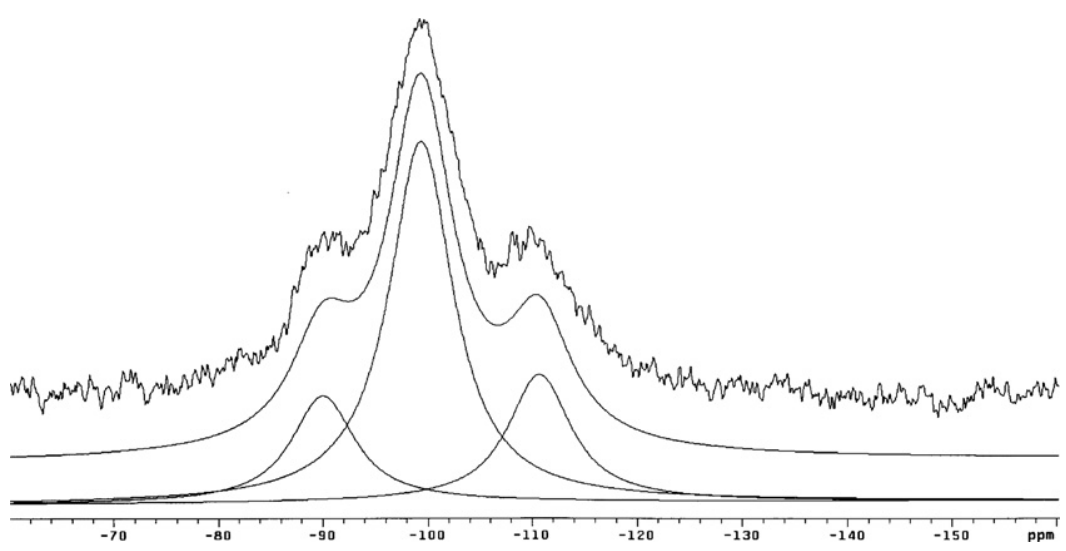

Fig. $8 .{ }^{29} \mathrm{Si} \mathrm{NMR}$ spectrum of xerogel coming from sodium silicate and quartz mixture. 


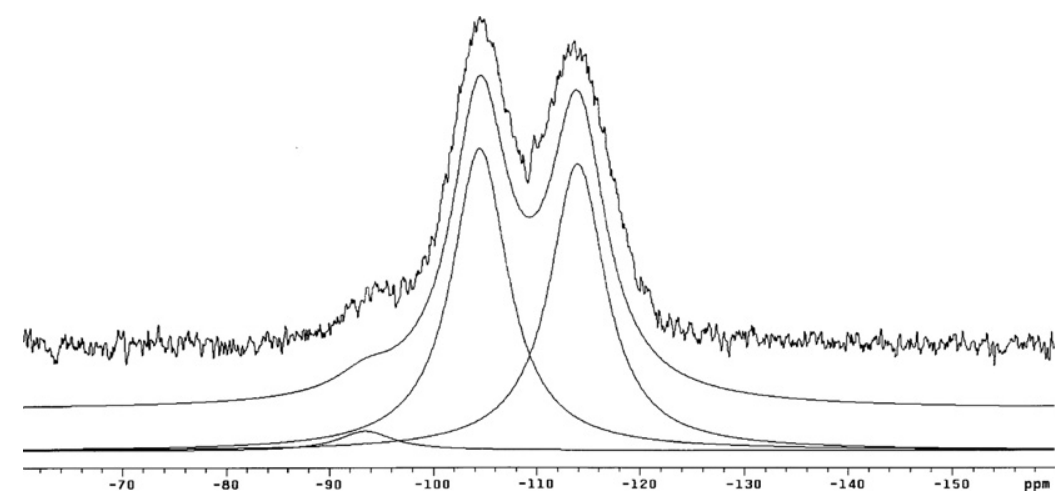

Fig. $9 .{ }^{29} \mathrm{Si} \mathrm{NMR}$ spectrum of xerogel coming from ethyl silicate and quartz mixture.

3.2.2.3. Ethyl silicate and quartz mixture. The presence of quartz involves a greater equilibrium between the planar and tri-dimensional structures (Fig. 9) that aid in a similar way to the total structure of the mixture (Table 2). The $\mathrm{Q}^{2}$ systems do not seem to feel the presence of quartz.

In general quartz modifies moderately the xerogel structure and the more significant changes are debited $\mathrm{Q}^{3}$ systems.

\subsection{Determination of products distribution into support}

The data obtained by mercury intrusion porosimetry show that the products can penetrate into mortars in $1 \mathrm{~cm}$ depth and only colloidal silica arrives at $1.5 \mathrm{~cm}$ depth. In particular Figs. 10 and 11 display how the xerogel from colloidal silica modifies in appreciable way the distribution of porous and show that the relative volume associable at the porous range of $100-300 \mathrm{~nm}$ decreases in drastic way in the first half centimetre. Besides the trend of the curve of the cumulative volume is increasing to lower values of porous ray and reveals a fraction of porous with little dimension which are always present because the product do not close them.

The sodium silicate shows a porosity trend similar to the non-treated mortars and it fills similarly all the hollows in the entire dimension range of porous considered.

The ethyl silicate shows a decrease of the cumulative volume of porous with a ray smaller than $200 \mathrm{~nm}$ but the trend of porosity is very similar to the non-treated mortars.

\subsection{Cohesion measure}

The diagram in Fig. 12 shows in ordinate the average values of the penetration velocity of the drill in $\mathrm{mm} / \mathrm{s}$ while in abscissa the depth expressed in $\mathrm{mm}$.

The penetration velocity of non-treated mortars samples decreases slightly with depth and the changes can be related with the low variations of cumulative volume between the internal and the external area of the mortar samples (around $20 \mathrm{~mm}^{3} / \mathrm{g}$ ). In all cases the products applied do not seem to involve significant cohesion changes under $1 \mathrm{~cm}$ depth.

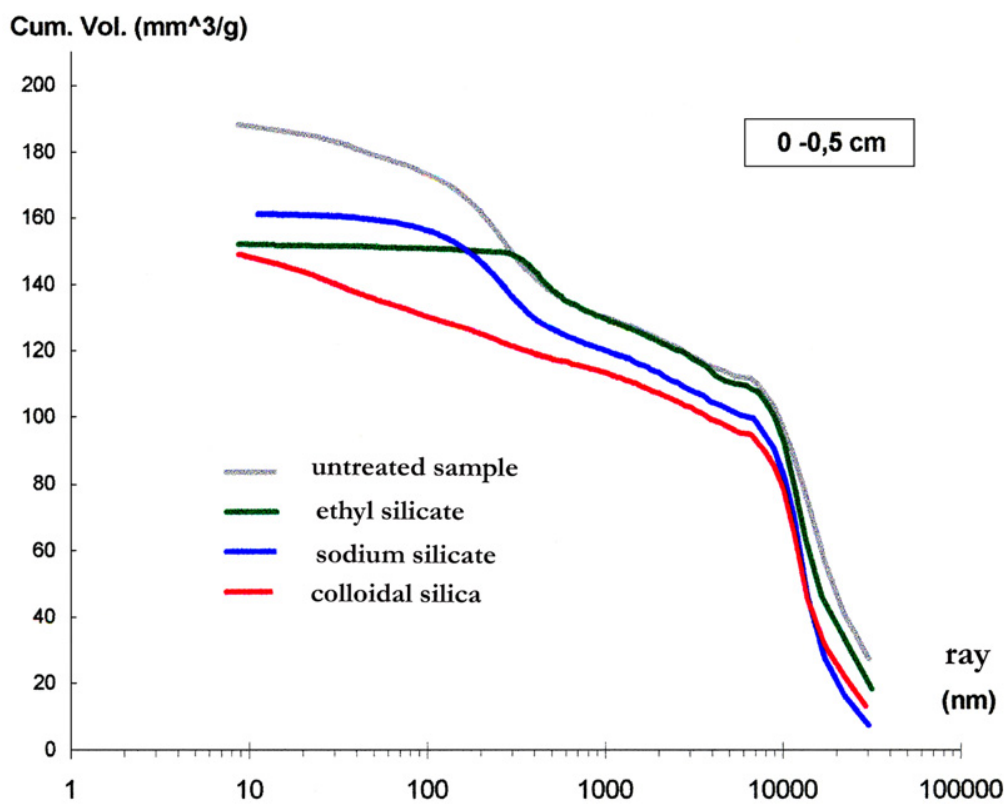

Fig. 10. Cumulative volume curve of the different products at $0-0.5 \mathrm{~cm}$ depth. 


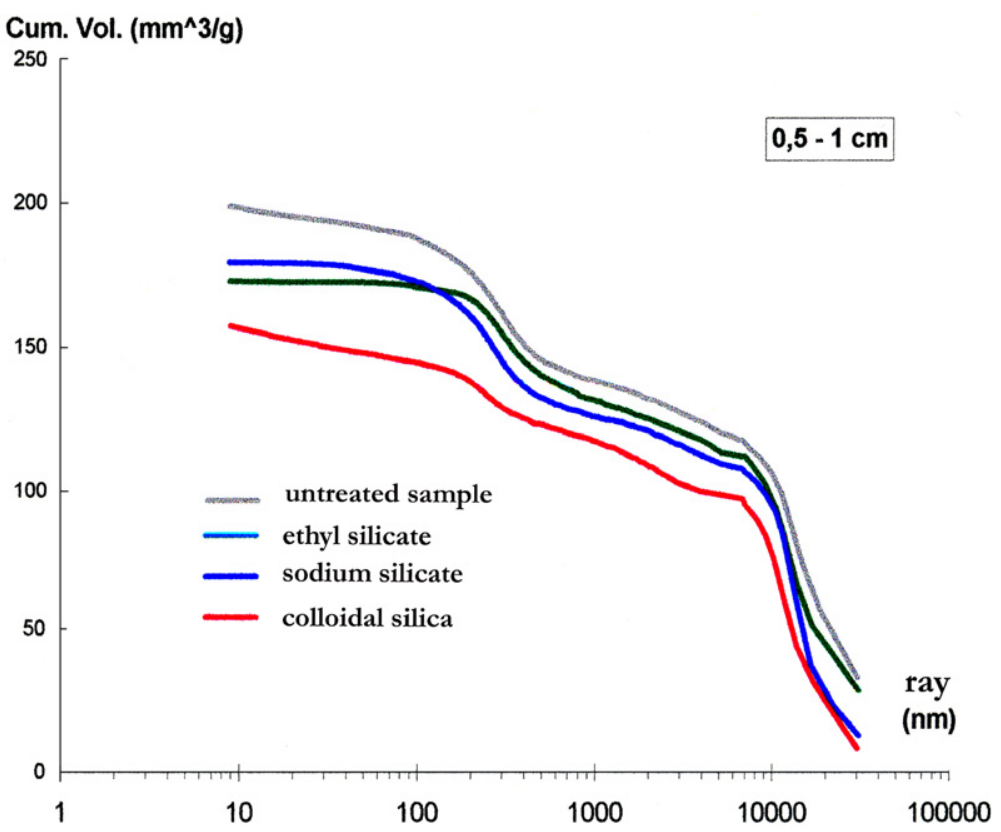

Fig. 11. Cumulative volume curve of the different products at $0.5-1 \mathrm{~cm}$ depth.

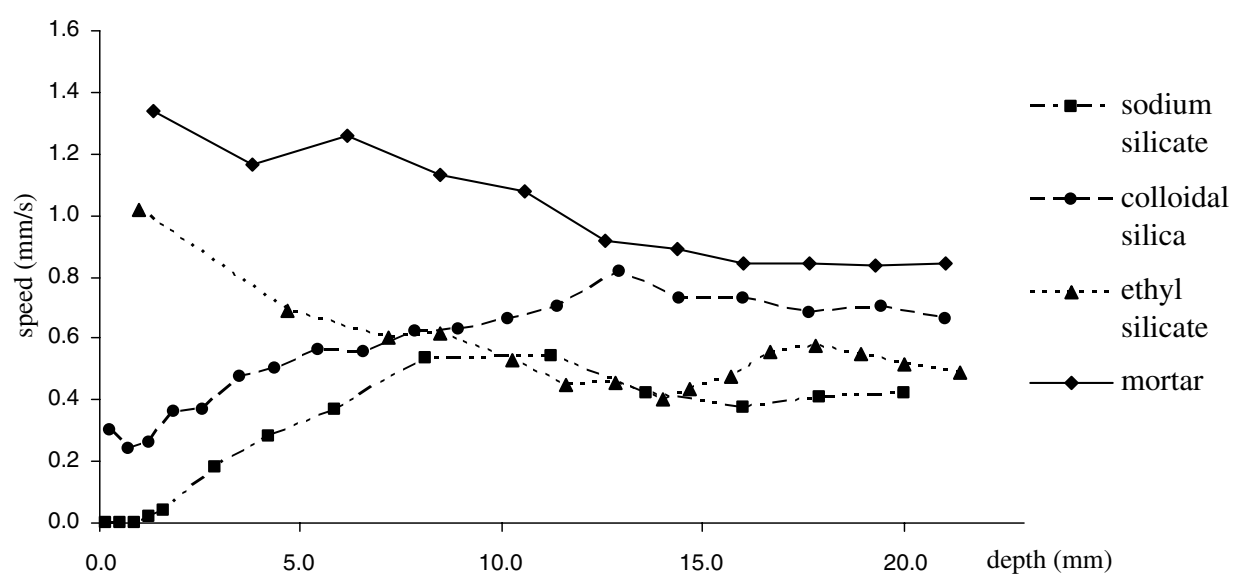

Fig. 12. Speed of drill penetration in function of the depth.

The samples treated with sodium silicate and colloidal silica display a less penetration velocity (less cohesion) in particular from the external surface until $10 \mathrm{~mm}$ in depth. Upon $10 \mathrm{~mm}$ the sodium silicate shows a weak cohesive action while colloidal silica reports values near the data of non-treated mortars [15]. The ethyl silicate seems to induce a moderate strength to penetration only below $10 \mathrm{~mm}$ in depth, with values near the data registered by sodium silicate. These measures do not seem to be correlated to porosity changes before discussed. In particular, the ethyl silicate and the sodium silicate show a different cohesive capacity in comparison with a similar porosimetric distribution. Although the colloidal silica penetrates more than the other products and modifies significantly the porosimetric distribution, it does not involve an increase of the cohesion on the material in the same manner of the sodium silicate.

\section{Conclusion}

Structural differences on silica produced by the three examined consolidants were revealed.

In xerogel coming from colloidal silica prevails the presence of $\mathrm{Q}^{4}$ systems related to tri-dimensional systems while in xerogels coming from ethyl silicate and sodium silicate prevail more planar "open" systems, much more available for a chemical interaction with calcium carbonate and quartz. The calcite reacts with xerogels involving significant structural modifications. In all cases the presence of $\mathrm{Q}^{3}$ systems seems to influence on the reactivity of the silicatic consolidants towards the support.

The consolidant based on ethyl silicate proves more reactive than others and this effect could offer good reasons for suppose that ethyl silicate has a best re-aggregating 
effect on substrate. On the contrary measures of cohesion on mortar samples treated with the three examined consolidants do not give great differences between the products and in particular, the ethyl silicate proves to have less cohesive effect on mortars than sodium silicate and colloidal silica. Instead the porosity distribution of treated samples evidences a greater penetration capacity of the colloidal silica, characterized by little dimensions of the particles in comparison with sodium silicate and ethyl silicate.

At this time we do not know how to quantify the phenomenon of the chemical reactivity to evaluate how much it really influences the consolidant effectiveness of the applied products.

It is important to suggest this study methodology using silicatic supports different from quartz in order to verify how the possible and different silicatic structures of the support can influence the reactivity with the consolidants.

Finally, we consider the chemical reactivity of quartz very important for the consolidation operation if it is developed in the application phase. The case of ethyl silicate is symbolic although it has not reactivity with the support: if ethyl silicate is applied in presence of humidity it reacts rapidly with water forming a compact superficial layer that compromises the result of the consolidation operation stopping the penetration of consolidant into the materials. The research of the reactivity will allow to reveal the chemical interactions also in long time in order to favour them or at last to create the best conditions for them to take place. In this sense the mixture between silica, calcite and quartz should be analyzed also after a period to study a possible reactivity in long-term.

\section{Acknowledgement}

The authors thank Prof. Vittorio Lucchini, Department of Environmental Sciences of Venice and MIUR-COFIN for the financial support of the work.

\section{References}

[1] Moropoulou A, Tsiourva Th, Michailidis P, Biscontin G, Bakolas A, Zendri E. Evaluation of consolidation treatments of porous stones, Application on the medieval city of Rhodes. In: Fourth international symposium on the conservation of monuments in the Mediterranean; 1997. p. 239.

[2] Domaslowski W, Lucaszewicz JW. Possibilities of silica application in consolidation of stone monument. In: Proceedings of sixth international congress on deterioration and conservation of stone, 12-14 September 1998, Torun. Nicholas Copernicus University Press; 1998. p. 563-76.

[3] Hansen E, Doehne E, Fidler J, Laron J, Martin B, Matteini M, et al. Review in Conservation, The International Institute for Conservation of Historic and Artistic Works, IIC. 2003; vol.4, pp. 13-25.

[4] Iler Ralph K. The chemistry of silica. John Wiley and Sons Ed; 1979.

[5] AA.VV. Science of ceramic chemical processing. New York: John Wiley \& Sons Ed, 1986.

[6] Camaiti M, Borselli G, Matteoli C. Prodotti consolidanti impiegati nelle operazioni di restauro. L'Edilizia, De Lettera Ed 1988;2:10.

[7] Danehey C, Wheeler GS, Su SCH. Tha influence of quartz and calcite on the polimerization of methyltrimethoxysilane. In: Proceedings of seventh international congress on deterioration and conservation of stone, 15-18 June, 1992, Lisbon.

[8] Zendri E, Lucchini V, Biscontin G, Morabito MZ. Interaction between clay and lime in cocciopesto mortars: a study by ${ }^{29} \mathrm{Si}$ MAS spectroscopy. Appl Clay Sci 2004;24(1-2):1-7.

[9] Cervantes J, Mendoza-Dìaz G, Alvarez-Gasca DE, Martinez-Richa A. Application of $29 \mathrm{Si}$ and $27 \mathrm{Al}$ magic angle sinning nuclear magnetic resonance to studies of the building materials for historical monuments. Solid State Nucl Mag Res 1999;13:263-9.

[10] Guiner A, Fournet G. Small angle scattering of X-rays. Wiley and Sons Ed; 1955

[11] Lippmaa E, Mägi M, Samoson A, Engelhardt G, Grimmer A-R. Structural studies of silicates by solid-state high-resolution ${ }^{29} \mathrm{Si}$ NMR. J Am Chem Soc 1980;102(25):4889.

[12] Grutzeck M, Benesi A, Fanning B. Silicon-29 magic angle nuclear magnetic resonance study of calcium silicate hydrates. J Am Ceram Soc 1989;72(4):665-8.

[13] Kirkpatrick RJ. ${ }^{29} \mathrm{Si}$ MAS NMR study of the structure of calcium silicate hydrate. Advn Cem Bas Mat Cong X 1996;3:144.

[14] ICR-CNR Raccomandazioni Normal 4/80.

[15] Zendri E, Biscontin G, Fortunati G, Driussi G. In: Mascolo G, editor. Proceeding of second national symposium materiali e tecniche per il restauro, Cassino (FR); 1999. p. 69-79. 